\title{
Propuesta teórico-metodológica para un análisis crítico y complejo del discurso (ACCD) en la prensa de Chile y Perú. El ejemplo de La Cuarta y Ajá ${ }^{1}$
}

\author{
Rodrigo BROWNE SARTORI \\ Universidad Austral de Chile (Valdivia) \\ rodrigobrowne@uach.cl \\ Carlos Del Valle Rojas \\ Universidad de La Frontera (Temuco, Chile) \\ delvalle@ufro.cl \\ Víctor SILVA ECHETO \\ Universidad de Playa Ancha (Valparaíso, Chile) \\ vsilva@upa.cl \\ Julio CARVAJAL RIVERA \\ Universidad Austral de Chile (Valdivia) \\ jcarvaja@uach.cl \\ Álex InZUlza MoragA \\ Universidad Austral de Chile (Valdivia) \\ alexinzunza@uach.cl
}

Recibido: 19/03/2010

Aceptado: 23/07/2010

\section{Resumen}

El objetivo de este artículo es proponer un diseño teórico-metodológico para un análisis comparativo, crítico y complejo del discurso entre la prensa de Chile y Perú: noticias publicadas en los diarios La Cuarta y Ajá, respectivamente. Como consecuencia del carácter complejo de las relaciones interculturales entre estos países, como estrategia metodológica, se aplicará una matriz centrada en un Análisis Crítico del Discurso (ACD) periodístico que recoja los resultados concretos de cada una de las noticias recurrentes entre ambos medios. En una segunda etapa, y desde las bases metodológicas del ACD, se propondrá un Análisis Crítico y Complejo del Discurso (ACCD) que habilitará una herramienta comparativa de matriz compleja que permita cotejar las diferencias y semejanzas arrojadas por los periódicos en cuestión.

Palabras clave: ACD, periodismo, interculturalidad, Perú-Chile

Theoretical-methodological proposal for a critical and complex discourse analysis (CCDA) in the Chilean and Peruvian press. The example of the newspapers La Cuarta and Ajá

\section{Abstract}

The goal of this article is to propose a theoretical-methodological design in order to develop a comparative, critical, and complex discourse analysis between the Chilean and the Peruvian press: news published in the newspapers "La Cuarta" and "Ajá", respectively. Due to the complex nature of the intercultural relationships between both countries, a matrix centred on a journalistic CDA will be

\footnotetext{
${ }^{1}$ Proyecto FONDECYT No 1100264 "Periodismo intercultural: Construcción de la noticia a través de un análisis crítico y complejo del discurso en la prensa diaria de cobertura nacional de Chile y Perú. El caso de El Mercurio y La Cuarta,y El Comercio y Ajá”. Comisión Nacional de Investigación Científica y Tecnológica (CONICYT). Ministerio de Educación de Chile.
} 
applied as methodological strategy. This, in turn, will bring together the concrete results of each of the recurrent news in both media. In a second stage, and following the methodological grounds of CDA, a critical and complex discourse analysis (CCDA) will be posed enabling a comparative tool of complex matrix which will allow weighing against the differences and similarities yielded by the aforementioned newspapers.

Key words: CDA, journalism, interculturality, Perú-Chile.

\section{Referencia normalizada}

BROWNE SARTORI, et al (2011): "Propuesta teórico-metodológica para un análisis crítico y complejo del discurso (ACCD) en la prensa de Chile y Perú. El ejemplo de La Cuarta y Ajá". Estudios sobre el mensaje periodístico. Vol. 17, núm. 1, págs.: 17-42. Madrid, Servicio de Publicaciones de la Universidad Complutense.

Sumario: 1. Propuesta teórica. 1.1. Introducción: comunicación y cultura. 1.2. Comunicación intercultural mediada. 1.3. El periodismo, la comunicación mediada y la cultura. 1.4. Periodismo intercultural. 1.5. Construcción social de la realidad: identidad y alteridad. 1.6. El periodismo como constructor de noticias. 2. Propuesta metodológica: análisis crítico y complejo del discurso periodístico. 2.1. Discurso y sociedad. 2.2. El ACD. 2.3. El carácter complejo del ACD. 2.4. Aplicación metodológica. 2.4.1. Primera etapa. 2.4.1.1. Plano significativo del texto. 2.4.1.2. Plano formal texto/contexto. 2.4.2. Segunda etapa. 2.5. Ejemplo de aplicación metodológica. 2.5.1. primera etapa. 2.5.2. Segunda etapa. 3. Conclusiones. 4. Referencias bibliográficas.

\section{Propuesta teórica}

\subsection{Introducción: comunicación y cultura}

Tomando como punto de partida, los trabajos realizados por Miquel RoDRIGO Alsina (1999 y 2001, Rodrigo Alsina ET AL, 2008) en relación a las comunicaciones en general y a las comunicaciones mediadas ${ }^{2}$ e interculturales en particular, es pertinente, en el marco de una fundamentación teórico-epistemológica, destacar las sinergias comunicativas que, como objeto de estudio para la propia disciplina, se desenvuelven en tres ejes fundamentales: 1) identidad cultural, 2) comunicación intercultural y 3) emociones en las comunicaciones y su correspondencia directa con los medios, especialmente, la prensa escrita (periodismo intercultural). En este sentido y de acuerdo a los planteamientos de la presente investigación, la construcción de identidad cultural y los procesos de comunicación intercultural se observan en las relaciones entre personas que tienen referentes culturales diferentes y que se perciben a sí mismas como parte de "otra cultura" (NAïr, 2002 y 2006).

Nourredine ACHIRI (2003) indica al respecto que conceptos como "nosotros" y "ellos" se presentan en oposición en los medios occidentales, asimilando en el

${ }^{2}$ Para Rodrigo Alsina (1997), en nuestros tiempos y debido al advenimiento de las TIC y de las nuevas construcciones de realidad social, la definición de comunicación no sólo debería quedarse en las concepciones en torno a la comunicación de masas, sino que, para ampliar los horizontes, cabría entenderla en el contexto de una comunicación mediada. Otros teóricos son más radicales y plantean la crisis de la mediación producto de la "espectacularización” de lo mediático (SANTANDER, 2005), de la autorreferencialidad (SodRÉ, 1996 y SANTANDER, 2005) y del acontecimiento como puesta en tensión postmediática (SODRÉ, 2009). 
“ellos” la cultura árabe-marroquí de la cual proviene dicho autor. Alejandro GRIMSON (2000: 125), por su parte, confirma lo anterior manifestando que es crucial pensar desde la conjunción de un nos/otros que se traduzca en la aceptación de olores, sabores, sonidos y palabras que "se activen para producir similitudes y fundamentalmente, diferencias". Uno de los primeros en acercar la cultura como comunicación y la comunicación como cultura es Edward T. HALL (1959), quien da pie para desarrollar un ambiente que estimula la cooperación y el entendimiento entre culturas diferentes, ajenas y distantes, asumiendo que la cultura es el medio de comunicación propio del hombre. Así, diversos/as investigadores/as contemporáneos/as retoman el concepto de "cosmovisión natural-relativa” (ScHUTZ y LUCKMAN, 2003), vinculado a la noción de acervo social de conocimiento, y a la teoría del otro generalizado (MEAD, 1973) para entender que "el sistema de significatividades de los periodistas y lectores es producto de un pacto arbitrario, elaborado y confirmado en una comunidad Nosotros" (Concepción SEPÚLVEdA, Rodrigo Alsina y Medina Bravo, 2008: 130).

En la actualidad, los enfoques de IsRAel Garzón (2002: web) caracterizan la función de encuentro e interrelación entre nos/otros a partir de la "sensibilidad a las diferencias culturales y una apreciación de la singularidad cultural; tolerancia para las conductas de comunicación ambiguas; deseo de aceptar lo inesperado; flexibilidad para cambiar o adoptar alternativas y expectativas reducidas respecto a una comunicación efectiva”. La comunicación intercultural se ha tornado en un tema de vital interés para los investigadores de las comunicaciones en el nuevo siglo, sobre todo para quienes reflexionan desde el cruce comunicación y cultura. Rodrigo Alsina (1997), en ese contexto, defiende dicha posición indicando que los nuevos aportes desde y para la comunicación intercultural se proyectan como parte de las siguientes acciones: 1) importancia cada día más creciente de los movimientos migratorios, 2) facilidad para viajar que estimula nuevos contactos con otras culturas, 3) conciencia de una mundialización producto de la globalización económica y comunicacional, 4) globalización que implica la intervención de organismos internacionales en conflictos regionales o nacionales, 5) el Estadonación ya no es el principal referente político o ha dejado de serlo y 6) multiplicación de conflictos interculturales. En relación a las ya mencionadas coordenadas en torno a la comunicación y la cultura, este autor propone una nueva forma de participar activamente en los conflictos y choques entre culturas (Mattelart y Mattelart, 1997; Romano, 2000), denominando comunicación intercultural mediada a una propuesta teórico-conceptual que tiende al encuentro y tolerancia entre "diferentes".

\subsection{Comunicación intercultural mediada}

La comunicación intercultural mediada es un espacio donde -sin ser su centro- se asume la intervención tecnológica y se habla de los procesos de mediación que se dan en la producción del mensaje, no sólo utilizando el medio como mero transmisor (como canal), sino que, además, validándolo como constructor de un discurso determinado en un contexto global/local. Con esto, Rodrigo Alsina (1999: 33) argumenta que las comunicaciones (de masas) ya no buscan transformarse en un 
universal homogeneizado y reduccionista, "sino sólo entender cada cultura a partir de su propio universo simbólico".

La comunicación intercultural mediada y sus particulares características evidencian que los medios de prensa se dejan llevar por los "discursos de autoridad", manteniendo el estado de la cuestión a la hora de consolidar construcciones de realidad y olvidando, dentro del rigor ético-periodístico, abrir espacios de convivencia y armonía entre diferentes actores de un hecho noticioso. "Sea cual sea el acontecimiento étnico, se busca, se entrevista, y por tanto, se cita al político, alcalde, agente de policía, policía u otro ‘experto' (blanco)” (vAN DiJK, 2006: 25).

Con el propósito de adentrarse un tanto más en las cuestiones de la prensa y sus construcciones sociales de la realidad -atendiendo a un Análisis Crítico y Complejo del Discurso (VAN DiJK, 1990, 1997, 1998, 2003a yb y DEL VALLE, 2004a, 2004b, 2006, 2008) como estrategia metodológica- se recuperará el "discurso de la diferencia” (BHABHA, 2002 y Mignolo, 2007) en las relaciones entre Perú y Chile que surge de la oposición directa y dicotómica con el "discurso de autoridad”, ya sea éste proveniente desde la prensa peruana para con la "realidad” chilena y viceversa.

Para acercar todo lo anterior al ámbito de la prensa de Chile y Perú, se considera necesario recuperar las nociones que se han expuesto en relación a un periodismo intercultural (ISRAEL GARZÓN, 2000 y 2004 y BROWNE, 2006 y 2008) que se cuestione dichas representaciones y construcciones, en el caso específico de este trabajo, de dos países del sur de América Latina en coherencia con las ya presentadas aproximaciones en torno a la comunicación intercultural mediada.

\subsection{El periodismo, la comunicación mediada y la cultura}

Es indudable que en la generación de actitudes positivas o negativas hacia otras culturas, uno de los papeles más importantes corresponde a los medios de comunicación ya que, como sostienen Estrella ISRAEL GARZÓn (2004 y 2006) y Andreu CASERo RIPOLlÉs (2004), la mayor parte de los conocimientos sociales y culturales -por tanto la mayor parte de nuestras opiniones- se construyen desde las informaciones que entregan los aparatos productores de noticias. Prácticamente todo lo que la mayoría de los hombres conocen de otras culturas diferentes a la suya es suministrado por reportajes, noticias, sitios web que, para efectos de esta investigación, se analizarán críticamente desde un periódico peruano y otro chileno de influencia nacional y sus repercusiones al momento de construir la realidad identitaria-cultural de esa nación limítrofe con Chile, sobre todo dentro de los ámbitos considerados, despectivamente desde los discursos de autoridad, como populares en cada uno de los países y medios de prensa mencionados. Cada día son más los investigadores que se detienen en el análisis de la prensa escrita en relación a los estudios entre culturas, en el contexto de una comunicación intercultural mediada. Tiempo atrás eran fundamentales los trabajos de Javier DE LuCAS (2003 y 2005) y Estrella ISRAEL GARZÓN (2000; 2002; 2004; 2006), quienes propusieron ciertos patrones fundamentales para ahondar en estos temas específicos. Ahora el número de académicos ha aumentado y la necesidad de investigar sobre este 
particular es cada vez más urgente, debido a los avances político-migratorios que se exponían anteriormente a partir de las reflexiones de Miquel RodRIGo Alsina (1999 y 2006 (a y b)).

En paralelo a los trabajos aportados por DE LuCAS e IsRaEL GaRzón, Mary NASH (2005: 97) observa con detención las representaciones culturales de alteridad y la construcción de un imaginario colectivo respecto al otr@ inmigrante en los discursos periodísticos de la prensa española del último tiempo. La autora sentencia que en ésta en general y salvo contadas excepciones "los inmigrantes pobres e ilegales eran identificados con un perfil de delincuentes, mientras 'los extranjeros bien' eran los jubilados del Norte que se compraban una casita en una urbanización de la costa mediterráneo o de las islas”. Siguiendo los postulados de NASH en España y descansando en ciertas investigaciones locales (BROWNE, 2006 y 2008), se puede advertir que los medios de comunicación cumplen un papel crucial en cuanto a liderazgos de opinión pública en el ámbito, sobre todo, de la comunicación intercultural mediada. Así lo confirma Antolín Granados MarTínez (2006: 60) al sentenciar que más que un tema socioeconómico, sociolaboral y sociocultural, la inmigración extranjera es sobre todo un fenómeno de impacto mediático de primera página: "Como tal fenómeno mediático, su traslación en la opinión pública tiene efectos contundentes: el número de noticias y, sobre todo, su tratamiento, produce preocupación, prevención y rechazo”. Ello quiere decir que los acontecimientos noticiosos, velados como representaciones culturales, configuran un universo de juicios y estereotipos respecto a nuestra sociedad y en relación a otras, especialmente si estas últimas comparten límites fronterizos que soportan los lindes de una identidad cultural, bajo el alero de un Estado-nación determinado (RETIS, 2003 y SILVA, 2003).

Néstor COHEN (2005), por su parte, realiza una interesante crítica al Estado y a su rol poco comprometido hacia la diversidad cultural y le reprocha intentar homogeneizar las diferencias y diluir los matices de las relaciones interculturales para llegar, en síntesis, al disciplinamiento (FoucAult, 1994) de la otredad. Se torna urgente, por lo expuesto con anterioridad, establecer procedimientos para favorecer el periodismo desde un contexto intercultural: "una apuesta por un periodismo de calidad en un mundo complejo y convergente donde la interculturalidad como pauta se configure como una necesidad creciente” (ISRAEL GARZÓN, 2002: web).

En su libro Dominación étnica y racismo discursivo en España y América Latina (2003), Teun VAN DIJK, en uno de sus apartados, se refiere particularmente al discurso mediático chileno. Al respecto sostiene que con la inmigración actual de Perú y Bolivia, hacia Chile, ha aumentado el racismo en el país y confirma que, en un breve catastro, se encontraron en agosto de 2002 más de 700 sitios en Internet que acreditaban este hecho en contra de la "diferencia" de estos países del altiplano. A lo largo de las páginas de esta publicación y como argumento para una discriminación hacia el y lo indígena (donde se incluye la tradición cultural peruano y boliviana), el autor demuestra cómo la prensa chilena ha marginado también a los habitantes del pueblo originario Mapuche, representándolos y construyendo socialmente una realidad dentro del país, tildándolos como bárbaros, borrachos, 
terroristas y extremistas. Acto seguido, vAN DIJK (2003a: 146) concluye que, al igual que en otros lugares "con la Iglesia, las Fuerzas Armadas y la empresa, los medios en Chile son muy conservadores, como es el caso del periódico de gran tirada El Mercurio, que apoyó tanto al dictador Pinochet como a su gobierno militar”.

Vicente Romano (2000) insiste en que siempre hay un sesgo tras el uso de los medios y esa decisión procede directamente desde aquellos grupos que se vinculan con el poder económico, político y social. Vale decir, las informaciones provenientes de estos medios que pasan a formar parte de la visión de mundo de una sociedad, con características distintivas asimiladas y cultivadas, están dirigidas e intencionadas con un fin determinado, "una intervención inconsciente en el material comunicativo con unos intereses muy concretos. Cualquier proceso de producción comunicacional, desde la elección del medio, la grabación, la mezcla y la distribución, es una intervención en el material existente” (RomANo, 2000: web). Por ello no sólo hay que conformarse con que los medios se refieran a otras culturas, sino que también hay que preocuparse de cómo representan esa diversidad cultural. Al respecto, variadas investigaciones se plantean metodologías de análisis que cuestionan la objetividad de los medios en el tratamiento de la diversidad cultural, no por la objetividad en sí misma, sino por el tratamiento que de ella realizan medios supuestamente de transparencia informativa por ejemplo, y sin muy lejos, el propio diario El País (Bueno Lajusticia, 2000; De Pablos Coello, 2008).

Así la diversidad no queda reducida a una simple promesa incumplida dentro los ejercicios periodísticos-culturales (Glasser, AWAD \& KIM, 2009). "Las informaciones periodísticas pueden destacar los elementos más inasimilables o deleznables de una cultura, provocando un efecto de rechazo de toda esta cultura y no, simplemente, de esos aspectos concretos. La conocida tendencia de este medio a destacar lo negativo debería atemperarse cuando se trata de describir culturas” (Rodrigo Alsina, 1999: 11).

Para que los medios puedan remediar estos discursos culturales que descansan en miradas histórico-contextuales, es importante que éstos, en el ámbito de una sociedad amplia y diversa, comprendan que la diferencia enriquece y no necesariamente molesta. "Conocer al otro cualquiera que sea su origen, condición, etnia, es un acto de comunicación” (ISRAEl GARZón, 2006: 35). Los medios de comunicación, especialmente la prensa escrita, y las escuelas formadoras de periodistas y licenciados en comunicación social deben asumir ciertos postulados que admitan la riqueza de un buen ejercicio periodístico-cultural, logrando superar los estereotipos entre unos y otros, ya sean estas relaciones intra o extrapaís. En consecuencia, ese es el proyecto que se sostiene desde el cruce entre comunicación (mediada), periodismo y cultura: periodismo intercultural.

\subsection{Periodismo intercultural}

El periodismo intercultural busca detectar las fuentes que producen ruido en estos intercambios. Los ruidos interculturales son producidos cuando no se entiende al "otro" tal como es y se trata de imponer un "discurso de autoridad" identitario que nace de la diferencia que se tiene hacia ese "extraño” (CASERo Ripollés, 2004). 
Parte de un pluralismo que debe ser entendido como un continuo cuestionamiento frente a las barreras impuestas entre naciones, sociedades, culturas, entre "nosotros" (como Mismos) y los "otros". La detección de ruidos en los procesos de comunicación intercultural mediada es vital para la consolidación de un periodismo intercultural que intenta, a su vez, proponer otras ideas que defiendan la diversidad dentro de la igualdad de derechos y oportunidades.

Para continuar y si se toman como fuente los estudios de Javier DE LUCAS (2003), NASH (2005) y GRANADOS MARTínEZ (2006), muchos de los encuentros entre culturas no se perciben de manera directa, ya que el carácter de mediación intercultural de la comunicación las hacen aproximarse a través de los medios de prensa, tornándose en ruidos que implican desigualdad, desequilibrio social e incomprensión: "Los ruidos interculturales no son sólo una cuestión cuantitativa, ni exclusivamente referida a la raza sino de minusvaloración, desprecio o rechazo a la mujer, al inmigrante, al viejo, al discapacitado, al judío, al negro, al enfermo de SIDA, al homosexual o al gitano [...] El ruido aumenta en ocasiones cuando se cruzan variables como raza, género y clase social” (ISRAEL GARZÓn, 2004: web). IsRAEL GARZÓn (2000) encuentra en el periodismo investigativo, mirado desde una óptica intercultural, una potencial iniciativa para subsanar este conflicto y activar nuevos procesos de interculturalidad comunicativa en el momento de la construcción de la realidad a través de los medios. Es necesario desarrollar un periodismo en la denuncia de la discriminación intercultural, resaltando que la docencia en periodismo intercultural es trascendental para que las sociedades que se tildan de democráticas vivan en sana convivencia en términos de participación y ciudadanía.

DRZEWIECKA y STEYN (2009), en ese marco, promocionan una formación donde se inste a los periodistas a conocer y respetar otras culturas, más allá de las consolidaciones de prejuicios y estereotipos que derivan de las construcciones de identidad, dando por sentado que los estudios sobre la identidad son centrales para la comunicación intercultural. Los medios, más allá de informar, deben inculcar respeto hacia culturas distintas. En consecuencia, los periodistas actuales deben palpar esta "nueva realidad" y, desde su propia construcción, habilitar espacios de diálogo intercultural y de participación de la diferencia. La alternativa propuesta por la comunicación intercultural mediada no es transformar los "discursos de la diferencia" en "discursos de autoridad", sino difundirlos como parte de un sistema comunicacional-periodístico global/local que asume las diferencias como reflejo de las complejas sociedades contemporáneas. Un claro ejemplo, podría ser la siguiente cita: "Tienen ese miedo a lo desconocido. Y como no se hacen políticas de integración, de sensibilización, sino que este alcalde y otros se han dedicado a crear alarma social día a día... A decir por la televisión local que los inmigrantes violan a nuestras mujeres, que nos roban...” (Mercedes García Fornieles, El País, 5 de agosto de 2001).

\subsection{Construcción social de la realidad: identidad y alteridad}

Asentado en los postulados elaborados en la primera parte de esta investigación y para lograr entender los conflictos interculturales desde la comunicación y el periodismo, es conveniente exponer algunas miradas en torno a la construcción de 
la noticia desde la construcción de identidades y, por ende, de alteridades. Para ello, es necesario aproximarse, brevemente, a ciertas concepciones teóricas que, desde los estudios sociológicos de Peter L. Berger y Thomas LucKMAnN, continuadores de las líneas fenomenológicas de Alfred ScHUTZ, se reconocen bajo el título de $L a$ construcción social de la realidad (1972).

Retomando algunas ideas de RoDRIgo Alsina (2001: 177), este autor precisa que el constructivismo es de suma importancia para asimilar socialmente estos conflictos ya que, a fin de cuentas, conlleva a un cambio de concepción en la forma de hacer comunicación y en sus aplicaciones en el periodismo: "Mientras que la teoría matemática de la comunicación se preocupaba fundamentalmente por la transmisión de la información, el constructivismo considera que lo fundamental es la producción de sentido, a partir de la interacción social”. El constructivismo -en el entendido que su objeto de estudio es la vida cotidiana- postula que no existe una sola realidad y que ésta, para cada individuo, depende de teorías, ideologías, convicciones personales y contextos culturales que se encuentren a mano. La principal realidad es la de la vida diaria y es a través del sentido común que se le da significado, "la realidad de la vida cotidiana es algo que comparto con los otros" (BERGER y LuCKMANN, 1972: 39).

El conocimiento es interpretado y, a su vez, construye realidades. La realidad, por tanto, se construye socialmente; sin embargo, hay que tener claridad acerca del contexto donde ésta se origina. Se deben estudiar los procesos sociales en donde se produce conocimiento y cómo éste llega a quedar establecido socialmente como realidad. Al mismo tiempo, es necesario preguntarse cómo este conocimiento orienta la conducta de los individuos en la vida cotidiana. Entonces, se puede asegurar que la sociedad es una construcción que realizan permanentemente los individuos de y en ella misma.

Al respecto, BERGER y LUCKMANN (1972: 68) analizan la sociedad como realidad objetiva: institucionalizada y legitimada. La realidad institucionalizada tiene su origen en la tendencia a la habituación (hábito) del ser humano. Esta institucionalización puede llegar a convertirse en una forma de control social: el procedimiento por el cual se llega a ser hombre se produce en una interrelación con un ambiente en movimiento y activo, "el ser humano en proceso de desarrollo se interrelaciona no sólo con un ambiente natural determinado, sino también con un orden cultural y social específico mediatizado para él por los otros significantes a cuyo cargo se halla". El mundo institucional, por lo mismo, requiere de la legitimación para poder justificarse y poder explicarse, elaborando -con esto y siguiendo a los autores recién mencionados- universos simbólicos.

En consecuencia, se puede apuntar que la identidad del individuo se delinea en los límites de una realidad objetiva que se resuelve en una construcción humana de ésta, surgiendo de la compleja relación entre individuo y sociedad. "La identidad se forma por procesos sociales. Una vez que cristaliza, es mantenida, modificada o aún reformada por las relaciones sociales. Los procesos sociales involucrados, tanto en la formación como en el mantenimiento de la identidad, se determinan por la estructura social” (BERGER y LUCKMANN, 1972: 216). 
Al igual que los discursos de la realidad, la identidad también es construida por la cultura y quienes participan socialmente de y en ella. La comunicación intercultural mediada expone un recorrido teórico y epistemológico que tiene como propósito cuestionar las miradas esencialistas en su correlación identidad-alteridad. Con esto, se defienden posturas sobre comunidades fronterizas y se detiene ésta en nuevas y activas miradas que se vinculan a las identidades y alteridades en el contexto de la comunicación (periodismo) intercultural. Las identidades, por tanto, son construidas y en esa construcción se entrecruzan distintos componentes como la historia social, la historia personal del individuo, el contexto en general y el grupo con el que le toca convivir. A todo ello hay que sumarle la influencia de las nuevas tecnologías y los medios de comunicación (Rodrigo Alsina, 1999, 2006, Silva, 2003 y GASCÓN I MARTín, 2005).

\subsection{El periodismo como constructor de noticias}

Aunque no son los únicos, los medios de comunicación son uno de los principales constructores de imágenes para la institucionalización de una identidad única y una cerrada alteridad (también única). La actividad periodística es parte fundamental de la construcción de la sociedad, está legitimada y funciona como manifestación de consensos sociales, presenta la realidad y permite su observación, comprensión, análisis y escudriñamiento (CASTILLO, 2008). Es así como la noticia se torna en una tecnología que produce la realidad, tomando como base un discurso verosímil que proviene de unidades artificiales -como son las fuentes- y naturales -como los hechos- de un acontecimiento noticioso, "con el objetivo de predecir determinadas repercusiones y mantener un control de la realidad social” (MAYORGA y GONZÁLEZ, 2005: 3) y, aún más, de la colonización de la vida en el mundo realginario (mezcla entre la realidad y lo imaginario) (SANTANDER, 2008).

RoDRIGo Alsina (1999), por su parte, defiende que el proceso de la construcción social de la realidad está completamente supeditado a la práctica productiva del periodismo. Es recomendable tener en cuenta que la realidad comprendida como construcción social es exterior e independiente de la práctica periodística; no obstante, dicha realidad es producida y transmitida por los propios medios de comunicación. Por lo mismo, Vázquez Medel (1999: 149) -inspirado en el trabajo de BERGER y LUCKMANN- indica que el periodismo escrito constituye una forma de institucionalización de los procesos de construcción social de la realidad: "surge como respuesta a nuevas necesidades de consensos sociales y se transforma al ritmo de nuevas posibilidades tecnológicas y económicas, y de nuevas interacciones”.

El periodismo en la actualidad se debe entender como una empresa, con sus prioridades económicas, cuyo objetivo principal es la producción y difusión de mensajes informativos (CARVAJAL, 2008), haciendo, especialmente, que estas noticias sean parte de un discurso construido que tenga como referencia la realidad o, por lo menos, una fracción de ella.

Miquel Rodrigo Alsina en su libro La construcción de la noticia (1989: 185) propone la siguiente definición para noticia: "Noticia es una representación social de la realidad cotidiana producida institucionalmente que se manifiesta en la 
construcción de un mundo posible”, desmenuzándola de esta manera: 1) la representación social es una actividad que implica la reproducción de las características de un objeto que se traduciría en una construcción mental de éste; 2) producida institucionalmente se refiere a que la noticia tiene tanta importancia en su producción como en su reconocimiento institucional que es llevado a cabo por un periodista que solidariza con "las reglas del juego", certificando y validando a la propia sociedad y 3) construcción de un mundo posible que hace referencia a los estados de cosas previstas por el lector, es decir, y desde un punto de vista narrativo, se puede afirmar que la construcción del discurso periodístico informativo supone la creación discursiva de un supuesto mundo posible: "De algún modo se puede comparar al periodista como una especie de lector privilegiado de acontecimientos, a partir de los cuales va construyendo mundos posibles que luego transmitirá al auditorio" (RoDRIGo Alsina, 1989: 187). Por esta razón, hay que analizar el rol que cumplen los medios de comunicación en la formación de los imaginarios o universos simbólicos de cada individuo y de un colectivo determinado, debido a que la configuración social es una construcción constante que se edifica con la interacción del entorno socio-cultural. Expuesto lo anterior, tiene total sentido lo afirmado por Maxwell McComBs (1996: 38), en su libro Influencia de las noticias sobre nuestras imágenes del mundo: "Las noticias influyen en muchas facetas de nuestra vida cotidiana. Nuestro modo de vestir para ir al trabajo, el camino que elegimos a veces para llegar a él, los planes del próximo fin de semana, nuestros sentimientos generales de bienestar o de inseguridad, el enfoque de nuestra atención hacia el mundo más allá de la experiencia inmediata y nuestras preocupaciones sobre los temas del día, están bajo la influencia de las noticias cotidianas”.

\section{Propuesta metodológica: análisis crítico y complejo del discurso periodístico}

\subsection{Discurso y sociedad}

El proyecto metodológico que se propone en este trabajo se formula desde la mixtura y cruce entre dos propuestas -una supeditada a la otra- de corte cualitativo vinculada a los estudios del discurso en su relación con las ciencias sociales -y en su interior, en específico, a los estudios de la comunicación y del periodismo- más que con la lingüística y la sociolingüística (van DiJK, 2002). Uno de ellos es el reconocido, particularmente en el campo de los medios de comunicación, Análisis Crítico del Discurso (ACD) ${ }^{3}$ (VAN DiJk, 1997; 1998; 2002, 2003 a y b y 2008); y el otro es el trabajo que ha desarrollado, en Chile y desde el ACD, Carlos DEL VALLE

${ }^{3}$ Para aclarar cualquier confusión conceptual en relación a esta estrategia, es preciso explicar que el Análisis del Discurso no es lo mismo que el Análisis Crítico del Discurso (ACD). El primero se caracteriza por ser una disciplina de la lingüística y basa su análisis en los componentes que forman el texto; en cambio el ACD analiza estos elementos de una forma integral, crítica y denunciante referente a temas tales como la discriminación, la desigualdad, el abuso de poder, la dominación, entre otros. En palabras de vAN DiJK (2002: 19): “El ACD presupone esas relaciones entre discurso y sociedad que acabo de resumir, pero va más allá de una sociología o psicología social del discurso. En el ACD el enfoque es sobre relaciones de poder, o más bien sobre el abuso de poder o dominación entre grupos sociales”. 
(2006) bajo el nombre de Análisis Complejo y Crítico del Discurso (ACCD).

En cuanto a las relaciones entre sociedad y discurso esgrimidas por VAN DIJK (2002), parece coherente comprender que es útil, para efectos de esta investigación y entre otras, ver en el discurso una razón apropiada para el estudio de la construcción de los hechos y acontecimientos sociales y sus representaciones (PotTER, 1998). El discurso, por tanto, que interesa en este trabajo es aquel que es potenciado en términos de construcción social de la realidad por los propios medios de comunicación. Con esto se entiende la noción de discurso desde una mirada compleja, mixta, diversa (VAN DIJK, 2003), amplia y heterogénea donde su relación con los medios permite "[...] la visibilización y espectacularización de la realidad" (IMBERT, 2006: 131), concibiendo, por supuesto, que los medios de comunicación son las mejores herramientas que tiene la sociedad contemporánea para reproducir la ideología del consenso y del poder, ya que construyen estructuras interpretativas que anuncian qué y cómo se debe comprender la realidad y el día a día que le da vida y sustento.

La complejidad que conlleva esta conjugación discurso-sociedad permite dilucidar cómo las construcciones mediáticas afectan directamente a la conformación identitaria de comunidades en general (MeYER, 2003) que, en este trabajo, se focalizan entre los discursos de la prensa peruana y chilena, a partir de un mismo acontecimiento noticioso y cómo éste se trata en las páginas de los periódicos seleccionados como objeto de estudio de cada país (La Cuarta en Chile y Ajá en Perú).

\subsection{El ACD}

La discriminación cultural y los ejercicios de poder en la representación de “discursos de la diferencia” (BHABHA, 2002 y Mignolo, 2007) en la prensa coinciden con los temas prioritarios del ACD y su directa relación con la sociedad y la cultura. El ACD es una práctica social contextualizada que se conforma, no sólo por elementos lingüísticos, sino también por dispositivos que el propio lenguaje oculta según la conveniencia de quien comunica el mensaje. El ACD es un enfoque que se preocupa de las condiciones discursivas, sobre todo cuando éstas se delatan en el abuso de poder ejercido por grupos dominantes. Dicho análisis, además, observa y estudia los patrones de acceso y potestad sobre contextos, géneros, como también de las estrategias discursivas de control mental, deteniéndose en el discurso y sus funciones en la sociedad y tratando de entender cómo ésta se expresa, representa, legitima o reproduce. Teun van DiJK (2002: 20) es enfático al indicar que el ACD "no se limita a los trabajos que explícitamente se llaman así, sino que también engloba todas las modalidades de investigación crítica que tienen que ver con el uso del lenguaje o con la comunicación, por ejemplo el área de estudio de las relaciones de género, o el estudio crítico de los medios de comunicación”.

El periodismo escrito, particularmente en Chile y en Perú, constituye una forma de institucionalización de los procesos de construcción social de la realidad. La actividad periodística ha sido un fuerte instrumento de legitimación. "Así pues, podemos establecer que los periodistas tienen un rol socialmente legitimado e 
institucionalizado para construir la realidad social como realidad pública y socialmente relevante” (RodRIGO AlsinA, 1999: 30).

Por esta razón, el ACD como herramienta metodológica es esencial para esta investigación y, bajo este impulso, poder descifrar lo implícito/explícito del discurso periodístico. "Cuando se emite o recibe un mensaje, no sólo es importante el significado de lo que se dice, sino también la intención, explícita o implícita...” (CEPEDA y Mujica, 2000: 21). Es decir, el discurso periodístico variará según el contexto -nivel contextual se le llamará en la matriz metodológica- que incluye factores tales como situación, lugar, tiempo, los discursos mismos, los participantes junto a sus roles sociales, institucionales así como sus representaciones mentales, finalidades, opiniones, actitudes e ideologías (FAIRClough, 2003, ZAPATA-BARRERO y VAN DIJK, 2008).

Para vAN DIJK (2008: 278) un rol trascendental a la hora de reproducir el discurso a través de representaciones sociales, como conocimiento, actitudes ideológicas, normas y valores que "por una parte puede ser una práctica discriminatoria social en sí misma, y por otra expresa y ayuda a reproducir las representaciones sociales negativas (prejuicios, etc.) que son las bases mentales socialmente compartidas de tales prácticas sociales” son los medios de comunicación y sus "puestas en escena”. Sobre lo mismo, los medios de comunicación son las instituciones que valiéndose de este discurso público, juegan el papel más preponderante en la reproducción de las representaciones sociales interculturales: "Los medios son actualmente la fuente más influyente de tendencias racistas, prejuicios y racismo” (VAN DIJK, 2008: 279).

En virtud a las perspectivas del ACD, se puede subrayar que los medios masivos promueven preferentemente los intereses del poder social de turno (VAN DIJK, 1990 y Meyer, 2003) y defienden el modelo liberal. En ese sentido, son rescatables las palabras de Ana María Miralles (2001) que acentúa la importancia que le ha dado el periodismo al proyecto liberal de la ciudadanía, privatizando a la propia opinión pública y acusando que las noticias sólo "leen” lo que hace el poder. Como se puede apreciar, el ACD es aplicable al estudio de los medios de circulación nacional, en relación con el tratamiento noticioso de los “discursos de la diferencia” tanto chileno como peruano.

\subsection{El carácter complejo del ACD}

El Análisis Complejo y Crítico del Discurso (ACCD) que se recupera de la propuesta de Carlos DEL VALLE (2005, 2006 y 2008) para elucidar la última parte del cruce metodológico que permita cotejar los mismos acontecimientos noticiosos publicados por medios de Chile y Perú respectivamente, se desprende de los postulados ya expuestos sobre el ACD por Teun VAN DiJK y descansa, además, en las perspectivas elaboradas por Jonathan Potter (1998) cuando identifica las representaciones discursivas a partir de las factualidades reconocibles en todo texto. Sucede lo mismo, con las proyecciones de Tomás RodRíGUEz ViLlasante (2008) a partir de la noción de matrices complejas (tetralémicas les llama el autor) que conjugan los dos planos (y sus niveles) de la aplicación metodológica basada en el ACD y cuestionan las lógicas simplistas y reduccionistas que tienden a superar las 
estructuras ideológicas, a través de la formulación de tópicos de texto (VAN DiJK, 2008) que discuten los "discursos de autoridad".

Con esto y tras la selección de los tópicos, la iniciativa, como nuevo y último paso metodológico, cotejará las construcciones y representaciones de los medios de cada uno de los países en análisis para que "de esta manera procuremos no destacar quién dijo cada cosa, aunque la gente lo pueda saber, sino cómo dar razones colectivamente sobre las paradojas de lo que habían dicho unos y otros" (RoDRíGUEZ ViLLASANTE, 2008: 404).

El ACCD pretende, por tanto, comparar, aproximar, cotejar, descubrir, revelar, distanciar, confrontar o divulgar (DEL VALLE, 2005, 2006 y 2008 y MAYORGA y LEÓN, 2007) conexiones que a menudo se encuentran implícitas o explícitas en los discursos, dependiendo del caso en particular. Su fin es escudriñar en cada texto para dar con estas manifestaciones que marcan la construcción y potenciales consecuencias de la noticia, en términos de representaciones sociales de la realidad (BERGER y LuCKMANN, 1972 y PotTER, 1998) que funcionan de manera altamente compleja, "como es el caso de los actores, roles, lugares simbólicos, valores temáticos, situaciones discursivas, fabricación de consensos, recorridos figurativos, lógicas de poder y matrices ideológicas” (MAYORGA y LEóN, 2007: 178).

El carácter complejo, en el contexto de esta investigación, permite el cruce comparativo de las noticias ya analizadas desde una reelaboración del ACD a partir de la selección de tópicos que se desprenden de la aplicación de la matriz metodológica que en los planos significado/texto (nivel temático y nivel de los significados locales) y formal/texto-contexto (estructuras formales sutiles y nivel contextual) arrojan resultados independientes por cada construcción mediática de realidad (Chile o Perú), siempre partiendo, como ya se anunció, desde el mismo acontecimiento noticioso que afecta, pasa y es parte de los intereses políticos, sociales y económicos de ambos países.

\subsection{Aplicación metodológica}

De acuerdo a lo expuesto y fundamentado anteriormente, se propone una metodología de investigación aplicada de carácter cualitativa hermenéutica sobre la base de dos etapas que están asociadas a los objetivos específicos del proyecto.

En una primera etapa: aplicación de la matriz que -basada en las estrategias metodológicas de, entre otros, Teun VAN DIJK (1990; 1996; 1997; 1998; 2003) y denominada Análisis Crítico del Discurso (ACD)- permite elucidar los discursos de la diferencia estereotipados por los medios de comunicación.

En una segunda etapa: aplicación de la lectura que, desde el ACD, se puede llevar a cabo en miras a un Análisis Crítico y Complejo del Discurso (ACCD) (DEL VALLE, 2005, 2006 y 2008), habilitando una herramienta comparativa, a través de la formulación de tópicos de textos (VAN DIJK, 2008), que permita cotejar las diferencias y semejanzas arrojadas por los periódicos sobre la construcción en común de acontecimientos noticiosos recurrentes que publican los medios de prensa, tanto chilenos como peruanos y sus consecuencias en términos de representación social de la realidad. 


\subsubsection{Primera etapa}

En esta etapa se aplicará una matriz para sustentar la primera parte del análisis de las informaciones referidas al tema de investigación. Se proyectarán -para luego corroborarse y validarse en la aplicación del resto de los pasos de la matriz- los tópicos de texto (VAN DIJK, 2008) más recurrentes, los significados explícitos e implícitos, así como las estructuras formales sutiles y las representaciones mentales de la memoria a largo plazo (nivel contextual). De esta manera, se esperan comprender las representaciones que estos medios de comunicación hacen en relación a los discursos sobre la diferencia (BHABHA, 2002 y Mignolo, 2007), considerando los estudios interculturales desarrollados desde la comunicación mediada y sus aplicaciones en el periodismo.

Se propone seguir un conjunto de pasos respetando categorías específicas de análisis. Éstas se aplicarán de lo general a lo particular (global a lo local) en aspectos formales y de significados, y se dividirán en cuatro niveles, presentados en dos planos:

\begin{tabular}{|l|l|}
\hline Plano Significado/texto & Nivel temático: significados globales \\
\hline & $\begin{array}{c}\text { Nivel de significados locales: } \\
\text { » De carácter implícito o indirecto } \\
\text { » De carácter explícito o directo }\end{array}$ \\
\hline Plano Formal/texto-contexto & Estructuras formales sutiles \\
\hline & Nivel Contextual \\
\hline
\end{tabular}

\subsubsection{Plano Significado/texto}

El primero de los planos que se evidencia en la matriz corresponde al Plano Significado/texto, donde se ubica un primer Nivel temático de significados globales y un segundo Nivel de significados locales. En el Nivel temático de los significados globales se busca conocer cuáles son los temas a los que se les da importancia en la noticia y que, posteriormente, en una segunda etapa, dilucidarán los tópicos de texto, intentando encontrar el "qué" y el "cómo": de qué trata la noticia y describir la manera en que lo realiza. Para este nivel, la tarea se facilita debido a la estructura de "pirámide invertida" (nota informativa) utilizada por los periodistas que sintetiza lo más importante de la noticia en el titular o en la entrada de cada una de éstas. En el nivel de los significados globales se aprecian los temas a los que se refiere la noticia y se presenta como una especie de resumen que incluye de "qué trata", de "qué habla" y "cómo" ésta se emite. Generalmente, no son reconocibles con tanta evidencia, por lo que deben ser inferidos del propio discurso o asignados a él.

De este primer Nivel temático se desprende, implícitamente, lo que van DIJK 
(2008) llama los tópicos del texto o variables. Para el autor estos tópicos o variables son importantes porque entregan una coherencia global al discurso y, además, es la información que es recordada de mejor manera, organizando la forma en que se representan los acontecimientos en las memorias personales de las experiencias del día a día y su correlación tiempo/espacio. El autor las divide en tres clases principales: inmigración/construcción de identidad - Instalación/recepción - crimen y violencia.

El segundo Nivel corresponde al de los significados locales. En éste se plantea analizar los discursos periodísticos mediante el significado concreto de las palabras. En el nivel se observan, mediante construcciones semánticas, re-presentaciones positivas de uno y negativas de "el otro". En este nivel de análisis se puede encontrar cómo se destacan las "buenas cosas" y se olvidan "las malas" y a la inversa, en relación a la diferencia cultural de, en este caso, un país limítrofe.

Este nivel está dividido en significados locales de carácter implícito o indirecto, es decir, en las noticias no se expresa "la diferencia" de manera evidente y es necesario inferirla, relacionando los significados de palabras del texto. Se hallan, por ejemplo, implicaciones, presupuestos, alusiones, ambigüedades, hipérboles, etc.

Los significados del discurso no se mencionan directamente ya que se presupone que los imaginarios ya están construidos y su labor específica es completar o deducir la información no dicha o implícita en la noticia entregada. En consecuencia, es parte del modelo mental del público y no está presente con evidencia en el texto analizado.

Por otra parte, en el nivel de los significados locales de carácter explícito o directo se presentan informaciones evidentes, que se encuentran expresadas con claridad en las palabras del texto. Esto permite observar qué o cuál palabra es la más utilizada por los medios de comunicación en determinadas informaciones, ya que dichas elecciones estilísticas también conllevan implicaciones ideológicas que pueden dar a entender la opinión del periodista y el medio de comunicación en general sobre el acontecimiento. Este nivel es mucho más común en los diarios de corte popular, por ejemplo, el siguiente titular del diario La Cuarta (18 de marzo 2008): “Acusan a cholito de embarazar a menor". Cholito es una referencia despectiva para con el peruano. Otro es el caso del diario Ajá (17 de marzo 2009): "Rotos se la llevan fácil”. Roto es una forma despectiva de referirse al chileno.

\subsubsection{Plano Formal/texto-contexto}

El segundo de los planos de la matriz propuesta corresponde al Plano Formal/textocontexto, que está dividido en Estructuras formales sutiles y el Nivel contextual. En las Estructuras formales sutiles lo que se investiga es cómo operan los aparatos ideológicos formales del discurso que pueden emitir falacias, omitir información crucial, construyendo modelos sesgados e interesados de acuerdo a los "discursos de dominación” y sus fuentes: se refiere a la construcción diaria de las realidades y cómo son percibidas. Con este análisis se encuentran discursos que difunden un hecho noticioso y que no se perciben, debido a su sutileza y al carácter indirecto de la semántica utilizada. Con esto se consigue activar un aparato ideológico invisible, 
motivado a partir de la información emitida. Se puede apreciar cómo la identidad de "el otro" se construye desde la realidad del "discurso de autoridad".

Por su parte en el Nivel contextual se investigan las representaciones mentales de la memoria. Es la memoria a largo plazo donde se almacenan los conocimientos y las opiniones sobre lo vivido. En síntesis, se refiere a lo que se recordará posteriormente, es el modelo mental que se construye a partir de lo emitido. Se diferencia de las estructuras formales sutiles en que este marco contextual, estas representaciones mentales asentadas y sobre las que se apoya el conocimiento de la realidad, descansan en cuestiones históricas, políticas, económicas y sociales que confirman el vínculo entre el discurso y la cultura (VAN DIJK, 2002).

\subsubsection{Segunda etapa}

Para llevar a cabo esta segunda y última etapa del presente proyecto metodológico, se propone aplicar un ejercicio comparativo que se especifica desde un Análisis Complejo y Crítico del Discurso (ACCD) que logre cotejar los mismos acontecimientos noticiosos publicados por medios de Chile y Perú, respectivamente.

Esta iniciativa, elaborada por Del VALLE (2005, 2006 y 2008) a partir de la aplicación del ACD en noticias y sentencias jurídicas, está compuesta por perspectivas desarrolladas por PotTer (1998) y RodríGUez Villasante (2008), tomando como eje la noción de matrices complejas que permite vincular los dos Planos y sus Niveles con la formulación de tópicos de texto (VAN DiJK, 2008) que, esbozados en la etapa $\mathrm{n}^{\circ} 1$ de esta metodología, rescatan los elementos recurrentes de las publicaciones en cuestión. Encuentro que se evidencia en el ejercicio comparativo que cruza los resultados, a modo de tópicos de texto, de la aplicación de la matriz ACD ( $1^{\text {a }}$ etapa) de Chile y Perú sobre un mismo acontecimiento noticioso publicado por los medios de prensa objeto de estudio de y en los países en comparación.

Cuando se habla sobre la metodología del análisis comparativo como matriz compleja (DEL VAlle, 2008 y RodRíGuez Villasante, 2008) se plantea que la función de este instrumento consiste en comparar dos o más casos con el fin de poner de manifiesto sus disparidades y conformidades recíprocas. Considerando lo anterior, en este trabajo se procura buscar las características similares o diferentes de lo que se va a cotejar. En el particular, las informaciones referidas al caso de estudio, para construir variables comparativas que sean aplicables a las noticias de ambos países y así obtener indicadores pertinentes para los propósitos de la investigación.

\subsection{Ejemplo aplicación metodológica}

\subsubsection{Primera etapa}

AJA 06/03/2009

http://www.aja.com.pe/aja/seccion.php?txtSecci_id=3\&txtNota_id=9666\&pag=25

Simon cuadra a Foxley

Bueno es culantro, pero no tanto 


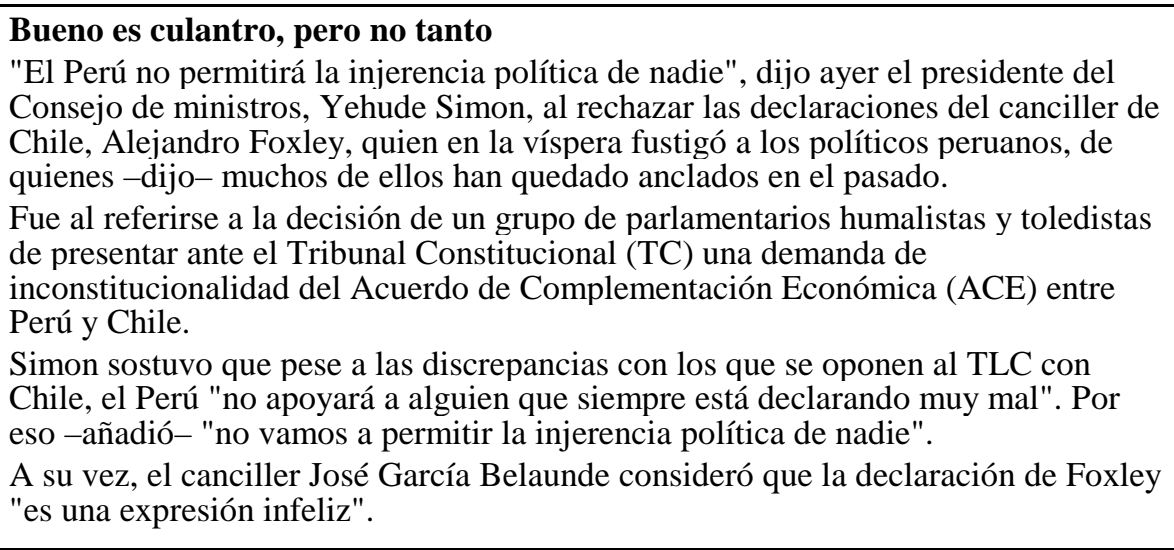

\begin{tabular}{|c|c|}
\hline Periódico: AJA & Día: 06/03/09 \\
\hline Sección & $\begin{array}{l}\text { Página web: } \\
\text { http://www.aja.com.pe/aja/seccion.php?txtSecci_id=3\&txtNota_id=9666\&pag } \\
=25\end{array}$ \\
\hline Titular & “Simon cuadra a Foxley” (Bueno es culantro, pero no tanto) \\
\hline \multicolumn{2}{|c|}{ 1. Plano Significado/texto Nivel temático } \\
\hline $\begin{array}{l}\text { 1.1. Nivel } \\
\text { Significados } \\
\text { globales }\end{array}$ & $\begin{array}{l}\text { La noticia trata de un problema político surgido por declaraciones del canciller } \\
\text { chileno Alejandro Foxley. El relato se cuenta con una marcada intención de } \\
\text { crear un ambiente que no existe y que es transformado por el periodista al } \\
\text { reelaborar el hecho que se está informando. Después de leer el título el lector } \\
\text { espera encontrar en la noticia cómo fue “cuadrado” el chileno, pero esto no } \\
\text { está en la historia contada, es decir no se cumple la promesa editorial, lo que } \\
\text { demuestra claramente que se está creando un escenario que no es real. } \\
\text { El tópico es uno de los propuestos en la investigación anterior: Política. }\end{array}$ \\
\hline \multicolumn{2}{|c|}{ 1. 2. Nivel de significados locales } \\
\hline $\begin{array}{l}\text { 1.2.1. De } \\
\text { carácter } \\
\text { implícito o } \\
\text { indirecto }\end{array}$ & $\begin{array}{l}\text { Implícitamente se da a entender que hay uno de los personajes de la } \\
\text { historia contada que está por sobre el otro, puesto que lo llama al orden, } \\
\text { a cuadrarse en jerga militar. }\end{array}$ \\
\hline $\begin{array}{l}\text { 1.2.2. De } \\
\text { carácter } \\
\text { explícito o } \\
\text { directo }\end{array}$ & $\begin{array}{l}\text { “Cuadra”: en el título, se utiliza esta expresión, en alusión a “poner en orden” } \\
\text { a otro. En este caso al canciller chileno por parte de una autoridad peruana. } \\
\text { "Fustigó”: conceptualmente el término está mal utilizado, dando a entender } \\
\text { una historia distinta de la que existió, con lo que se crea una animadversión } \\
\text { hacia el otro. } \\
\text { "Expresión infeliz”: se saca una parte de la declaración del canciller peruano y } \\
\text { al estar descontextualizada queda la idea que se refiere en términos duros a su } \\
\text { par chileno. (La cita completa: "Es una expresión infeliz. Uno no puede } \\
\text { descalificar con una frase una posición en la cual uno no cree. No puede Chile } \\
\text { sugerir que esa gente está anclada en el pasado. Me parece que es poco } \\
\text { afortunada la expresión, nada más", dijo el jefe de la diplomacia peruana al } \\
\text { diario El Comercio). }\end{array}$ \\
\hline
\end{tabular}




\begin{tabular}{|l|l||}
\hline \hline 2. Plano Formal/texto-contexto \\
\hline \hline $\begin{array}{l}\text { 2.1. Estructuras } \\
\text { formales sutiles }\end{array}$ & $\begin{array}{l}\text { Para justificar la elección de esta historia, que aparentemente no tiene mayor } \\
\text { trascendencia, sino que busca deliberadamente “crear” un ambiente belicoso } \\
\text { que no existe, se utiliza un término que implica algo más que unas } \\
\text { declaraciones de un personero público: “Fustigar”: flagelar, azotar, disciplinar, } \\
\text { pegar, golpear, lo que claramente el político chileno no hizo. }\end{array}$ \\
\hline \hline $\begin{array}{l}\text { 2.2. Nivel } \\
\text { contextual }\end{array}$ & $\begin{array}{l}\text { Utiliza el contexto histórico-político-social, casi nacionalismo mal entendido. } \\
\text { Lo hace tomando las declaraciones del personero peruano y dando a entender } \\
\text { que a pesar de que las declaraciones del canciller chileno apuntan a un sector } \\
\text { político distinto de quien habla, es necesario unirse en contra de quien está } \\
\text { atacando el estado peruano: “...pese a las discrepancias con los que se oponen } \\
\text { al TLC con Chile, el Perú ‘no apoyará a alguien que siempre está declarando } \\
\text { muy mal’...” }\end{array}$ \\
$\begin{array}{l}\text { Para reforzarlo, en dos oportunidades se repite la cuña de un personero } \\
\text { peruano que dice que no se va a permitir la “injerencia política de nadie”, lo } \\
\text { cual no es común en una nota tan breve. }\end{array}$ \\
\hline \hline
\end{tabular}

LA CUARTA 06/03/09 http://www.lacuarta.cl/contenido/66_32494_9.shtml

Canciller jaguar criticó a personeros peruanos por pelar TLC con Chile: Les dijo que son del siglo XIX.

Foxley saca ronchas entre gobierno y políticos cholitos.

-Pese al revuelo, La Moneda le prestó todo el ropero, hasta con chalecos antibalas.

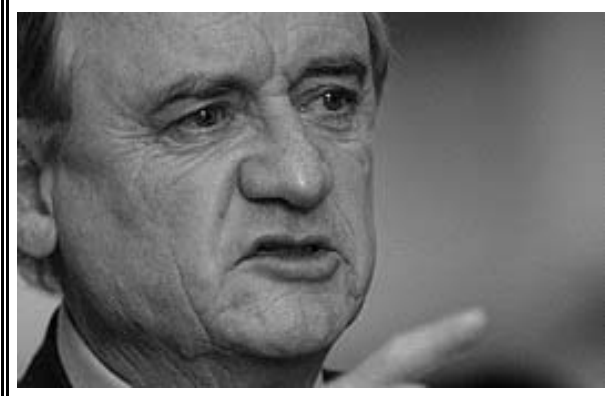

ESTÁ DE MIEDO: Sin enojarse, tranquilito, muy en su estilo, el ministro de Relaciones

Exteriores, Alejandro Foxley, mandó a freír monos a los políticos retrógrados del vecino país. Quedó la escoba, pero tiene todo el respaldo de La Moneda.

Está la cola otra vez en las relaciones de Jaguarlandia y Perú, tras la batahola que causaron en Lima las declaraciones del canciller Alejandro Foxley, quien criticó a los políticos cholitos contrarios al Tratado de Libre Comercio (TLC) con nuestros hermanos del norte.

Don Jano dijo el miércoles en radio Cooperativa que "hay políticos (peruanos) anclados en el siglo antepasado".

Por su litro y desde El Cairo, en Egipto, el canciller peruano, José Antonio García Belaúnde, le lanzó toda la artillería a Foxley. 
"Es una expresión infeliz. Uno no puede descalificar con una frase una posición en la cual uno no cree. No puede Chile sugerir que esa gente está anclada en el pasado. Me parece que es poco afortunada la expresión, nada más", dijo el jefe de la diplomacia peruana al diario El Comercio. Lueguito se sumaron las declaraciones del jefe del Consejo de Ministros de Perú, Yehude Simon, quien dijo que su gobierno no aceptará "injerencia política de nadie".

Pa ponerle más color al tete, el principal partido de oposición peruano pidió ayer una condena del parlamento a los "ataques" de Foxley.

\section{TODO EL ROPERO}

No obstante la zalagarda que proviene de Lima, el Gobierno le prestó todo el clóset a Foxley. Por boca del ministro vocero de Palacio, Francisco Vidal, la cosa viene así: "Cuando habla el canciller en materia de política exterior habla el Gobierno (...) El canciller tiene toda la experiencia para determinar cuál es el nivel de sus opiniones, pero sin duda, si él las ha dicho y ha opinado sobre este tema, tiene el respaldo del Gobierno".

Apañando también salió el senador UDI Hernán Larraín quien lanzó que la sobrerreacción chola sólo está fundada en "el rencor".

Ante el cerrado apoyo, el gobierno de Alan García optó por no hacer ningún reclamo oficial, sólo la ráfaga de declaraciones.

\begin{tabular}{||l||l|}
\hline \hline $\begin{array}{l}\text { Periódico: LA } \\
\text { CUARTA }\end{array}$ & Día: 06/03/09 \\
\hline \hline Sección: & Página: http://www.lacuarta.cl/contenido/66_32494_9.shtml \\
\hline \hline
\end{tabular}

Titular:

Canciller jaguar criticó a personeros peruanos por pelar TLC con Chile: Les dijo que son del siglo XIX

FOXLEY SACA RONCHAS ENTRE GOBIERNO Y POLÍTICOS CHOLITOS

-Pese al revuelo, La Moneda le prestó todo el ropero, hasta con chalecos antibalas.

\section{Plano Significado/texto Nivel temático}

\begin{tabular}{|l||l|}
\hline \hline $\begin{array}{l}\text { 1.1. Nivel } \\
\text { Significados } \\
\text { globales }\end{array}$ & $\begin{array}{l}\text { La noticia trata de un problema político surgido con Perú debido a } \\
\text { declaraciones del canciller chileno Alejandro Foxley. El relato tiene un } \\
\text { tono irónico y se posiciona dando a entender de manera solapada que hay } \\
\text { uno superior al otro. } \\
\text { El tópico es uno de los propuestos en la investigación anterior: Política. }\end{array}$ \\
\hline
\end{tabular}

\section{2. Nivel de significados locales}

\begin{tabular}{|c|c|}
\hline $\begin{array}{l}\text { 1.2.1. De carácter } \\
\text { implícito o indirecto }\end{array}$ & $\begin{array}{l}\text { Se usan las comillas para marcar una ironía, específicamente al referirse a los } \\
\text { "ataques” del canciller. } \\
\text { A lo largo del texto se usan expresiones que implícitamente dan la idea que } \\
\text { Chile es un mejor lugar. Además de estar constantemente desacreditando a } \\
\text { los peruanos con expresiones de carácter explícito. } \\
\text { Es decir, acá tenemos una presentación positiva de los chilenos y negativa de } \\
\text { los peruanos. }\end{array}$ \\
\hline $\begin{array}{l}\text { 1.2.2. De carácter } \\
\text { explícito o directo }\end{array}$ & $\begin{array}{l}\text { Hay uso de expresiones que ponen a Chile por sobre Perú: Canciller jaguar, } \\
\text { jaguarlandia. También se usan palabras que desacreditan a los peruanos: } \\
\text { cholitos, sobrerreacción chola, políticos retrógrados. } \\
\text { Hay uno que es superior al otro puesto que los “mandó a freír monos”, } \\
\text { expresión utilizada para decirle a alguien que está hablando sin sentido. } \\
\text { Se usa el término zalagarda para calificar la actitud de los peruanos y el } \\
\text { concepto refiere a emboscada, celada, trampa, ardid, chanchullo, es decir } \\
\text { son tramposos. Esto se demuestra al señalar que a pesar de todo el } \\
\text { canciller, tiene "todo el respaldo" del gobierno chileno. }\end{array}$ \\
\hline
\end{tabular}




\begin{tabular}{||l|l||}
\hline \hline 2. Plano Formal/texto-contexto \\
\hline \hline 2.1. Estructuras \\
formales sutiles & $\begin{array}{l}\text { Construye en el lector una idea determinada de cómo son en Perú: son } \\
\text { exagerados y sin motivo. Puesto que ante esta “sobrerreacción chola”, el } \\
\\
\text { gobierno “le prestó todo el closet a Foxley”, es decir lo respalda. Esto se } \\
\text { apoya con declaraciones del vocero de gobierno y un político de oposición, } \\
\text { para terminar diciendo que a pesar de todo “Alan García optó por no hacer } \\
\text { ningún reclamo oficial” quedando en el inconsciente que sólo son } \\
\text { exageraciones. }\end{array}$ \\
\hline \hline $\begin{array}{l}\text { 2.2. Nivel } \\
\text { contextual }\end{array}$ & $\begin{array}{l}\text { Se utiliza el contexto histórico asentado por años en la memoria de los } \\
\text { chilenos sobre que este país es el “Jaguar de América”: Canciller Jaguar, } \\
\text { jaguarlandia. }\end{array}$ \\
\hline \hline
\end{tabular}

\subsubsection{Segunda etapa}

\section{Plano 1 Significado/texto}

En este caso, en las noticias seleccionadas se encontró uno de los tópicos sugeridos en la investigación previa, que hace referencia a temas políticos entre ambos países.

\begin{tabular}{|l||c||c||}
\hline \multicolumn{2}{|l|}{ Nivel Significados globales } \\
\hline \hline Variables / Tópicos de texto & Perú & Chile \\
\hline \hline -Temas de política (binacional) & 1 & 1 \\
\hline
\end{tabular}

\begin{tabular}{|c|c|c|}
\hline \multicolumn{3}{|c|}{ Nivel de significados locales } \\
\hline & Perú & Chile \\
\hline $\begin{array}{l}\text { De carácter } \\
\text { implícito o } \\
\text { indirecto }\end{array}$ & $\begin{array}{l}\text { Se refiere, en una ocasión, a los } \\
\text { personajes de la historia por sobre el } \\
\text { otro. }\end{array}$ & $\begin{array}{l}\text { Se usa ironía y expresiones que dan a } \\
\text { entender que Chile es mejor lugar. } \\
\text { Se desacredita a los peruanos. Hay } \\
\text { presentación positiva de los chilenos y } \\
\text { negativa de los peruanos. }\end{array}$ \\
\hline $\begin{array}{l}\text { De carácter } \\
\text { explícito o } \\
\text { directo }\end{array}$ & $\begin{array}{l}\text { Hay un alguien superior a otro. Se } \\
\text { mal utilizan términos y se } \\
\text { descontextualiza una cita. }\end{array}$ & $\begin{array}{l}\text { Hay uso de expresiones explícitas que } \\
\text { ponen a Chile por sobre Perú, y que } \\
\text { desacreditan a los peruanos. }\end{array}$ \\
\hline
\end{tabular}

\section{Plano 2 Formal/texto-contexto}

\begin{tabular}{||c|c||}
\hline \multicolumn{2}{|c||}{ Estructuras formales sutiles } \\
\hline \hline \multicolumn{1}{|c||}{ Perú } & Chile \\
\hline \hline $\begin{array}{l}\text { Exageran lo que hizo un político chileno para } \\
\text { construir una idea equivocada del otro país. }\end{array}$ & Destaca lo exagerados que son en Perú. \\
\hline \hline
\end{tabular}

\begin{tabular}{|c|c|}
\hline \multicolumn{2}{|c|}{ Nivel contextual } \\
\hline Perú & Chile \\
\hline $\begin{array}{l}\text { Utiliza el contexto histórico-político-social: hay } \\
\text { que defenderse frente a un ataque extranjero. }\end{array}$ & $\begin{array}{l}\text { Se utiliza el contexto histórico: jaguares de } \\
\text { América para destacar que Chile es mejor. }\end{array}$ \\
\hline
\end{tabular}




\section{Conclusiones}

Una conclusión inicial de la aplicación metodológica, en su primera etapa, y su contextualización teórica revela que los dos medios de comunicación analizados entregan una construcción noticiosa mediada, interpretando, a partir de imaginarios y estereotipos, lo que se diagnóstica mediante el Análisis Crítico y Complejo del Discurso (ACCD).

Por lo tanto, en esta primera parte se puede señalar el cómo estos medios reelaboran la realidad a través de las noticias que emiten, con temáticas referidas a los acontecimientos que describen las relaciones interculturales y de las minorías, es decir, se logran comprender los procesos de construcción noticiosa y las representaciones que los dos medios estudiados hacen en relación a los discursos sobre los otros.

Se puede inferir, en términos generales y basándose en la investigación previa, que este esquema de análisis es lo suficientemente pertinente para analizar estos mensajes periodísticos y comprender cómo los medios de comunicación producen noticias como herramientas que logran construir estereotipos sociales, realidades que crean y refuerzan modelos mentales (VAN DIJK, 2008).

Respecto de la segunda etapa del análisis, se propuso realizar una comparación que logre confrontar acontecimientos noticiosos referidos a la misma temática publicados por medios de Chile y Perú.

En el primer Plano Significado/texto se busca conocer cuáles son los tópicos más recurrentes y se determinan si son de carácter explícito o implícito. En el segundo nivel de la matriz, Plano Formal/texto-contexto, se busca saber cuáles son las nuevas representaciones mentales de la memoria que permanecen en el lector y cuáles descansan en cuestiones históricas ya sean políticas, económicas o sociales. A la larga, la idea es que estos datos entreguen una media, un valor cuantificable que permita determinar la recurrencia de los estereotipos e imaginarios más utilizados por los periódicos de ambos países.

Si se proyecta esta propuesta en el marco de un análisis general -como lo estipulado en el proyecto para 2010- se podrá observar que la investigación permite comparar y determinar cuáles son los tópicos más redundantes entre las noticias de ambos países. Tópicos que se desprenden de la aplicación de la matriz metodológica en sus dos planos, tal como se expuso en el ejemplo mencionado en este artículo.

\section{Referencias bibliográficas}

ACHIRI, Noureddine (2003): “El discurso de la prensa sobre inmigración en España y Marruecos: dos perspectivas y dos modos de argumentación” en LARIO, Manuel (2006): Comunicación, cultura y migración. Sevilla, Junta de Andalucía. AUSTIN MILLÁN, Tomás (2004): “Comunicación Intercultural: fundamentos y sugerencias” en Diálogos en la acción. Disponible en: http://www.angelfire.com/ emo/tomaustin/intercult/comintuno.htm [fecha de consulta: 27 de febrero 2010]

BERGER, Peter L. y LUCKMANN, Thomas (1972): La construcción social de la realidad. Buenos Aires, Amorrortu. 
BERIAIN, Josetxo y LANCEROS, Patxi (1996): La construcción de la identidad colectiva en las sociedades modernas. Bilbao, Universidad de Deusto.

BHABHA, Homi (2002): El lugar en la cultura. Buenos Aires, Manantial.

BROWNE, Rodrigo (2002): Towards an anthropophagous intercultural communication. 23rd Conference and General Assembly of the International Association for Media and Communication Research. "Intercultural Communication"(IAMCR/AIECS/AIERI). Barcelona.

- (2006): Comunicación intercultural y periodismo de actualidad. (In)disciplinas e (in)definiciones para una deconstrucción crítica de los medios en RODRIGO ALSINA, Miquel (coord.): Comunicación Revista Internacional de Comunicación Audiovisual, Publicidad y Estudios Culturales, nº 4. Monográfico sobre “Comunicación Intercultural”. Universidad de Sevilla, pp. 223-242.

- (2009): De la comunicación disciplinaria a los controles de la comunicación. Sevilla, Alfar.

BROWNE, Rodrigo; INZUNZA, Alex y VALENZUELA, Víctor Hugo (2008): "Periodismo intercultural: aproximaciones teórico-metodológicas para un análisis crítico de la construcción social de los medios de comunicación” en CARVAJAL, Julio y RODRÍGUEZ, Gustavo (2008): La información periodística y sus aplicaciones. Buenos Aires, Gran Aldea.

BUENO LAJUSTICIA, María del Rosario (2000): "Estructura textual, macroestructura semántica y superestructura formal de la noticia”. Estudios sobre el Mensaje Periodístico, $\mathrm{n}^{\circ}$ 6. Madrid, Servicio de Publicaciones de la Editorial Complutense, pp. 239-258.

CASERO RIPOLLÉS, Andreu (2004): “Informando del 'Otro': estrategias del discurso periodístico en la construcción de la imagen en los inmigrantes” en Sphera Publica, $\mathrm{n}^{\circ}$ 4, Universidad Católica de Murcia, pp. 221-236.

CARVAJAL, Julio (2008): "Productividad informativa en situaciones de crisis social: los casos de ABC, El País y La Razón durante el 11-M” en Estudios sobre el Mensaje Periodístico, $\mathrm{n}^{\circ}$ 14. Madrid, Servicio de Publicaciones de la Editorial Complutense, pp. 99-109.

CASTILLO, Ana María (2008): “Análisis Crítico del Discurso de la construcción intercultural mapuche, peruana y boliviana en la prensa de cobertura nacional. El caso de los diarios 'Las Últimas Noticias' y 'La Cuarta' durante el trimestre marzo-mayo de 2008”. Tesis para optar al grado de Magíster en Comunicación, Facultad de Filosofía y Humanidades, Universidad Austral de Chile (Valdivia).

CEPEDA, Gladys y MUJICA, Gladys (2000): "Ejemplo de un análisis crítico del discurso" en Documentos Lingüísticos y Literarios, Instituto de Lingüística y Literatura, Facultad de Filosofía y Humanidades, Universidad Austral de Chile, $\mathrm{n}^{\circ}$ 23. Valdivia, pp. 21-28.

COHEN, Néstor (2005): "El rol del Estado ante las migraciones recientes desde la perspectiva de la población nativa" en Relaciones interculturales: experiencia y representación social de los migrantes. Buenos Aires, Universidad de Buenos Aires. 
CONCEPCIÓN SEPÚLVEDA, Luis Gilberto; RODRIGO ALSINA, Miquel y MEDINA BRAVO, Pilar (2008): "Niveles semánticos de las representaciones sociales de la inmigración subsahariana. Los sucesos de Ceuta y Melilla según ABC” en Estudios sobre el Mensaje Periodístico, n 14. Madrid, Servicio de Publicaciones de la Editorial Complutense, pp. 129-148.

DE LUCAS, Javier (2003): Globalización e identidades. Claves políticas y jurídicas. Barcelona, Icaria.

- (2005): "Los discursos sobre la inmigración: la ausencia de la ciudadanía” en Jornadas "Los modos y los medios": Reflexiones para un periodismo intercultural, Sevilla, Pabellón de Uruguay.

DEL VALLE, Carlos (2004a): “Genealogía crítica de la comunicación intercultural: mediocentrismo e invisibilización de lo étnico en los estudios interculturales" en Sphera Publica, nº 4. Universidad Católica de Murcia, pp. 171-196.

- (2004b): Metainvestigación de la Comunicación en Chile. Tendencias y crítica. Temuco, Ediciones Universidad de La Frontera.

- (2005): "Interculturalidad e intraculturalidad en el discurso de la prensa. Cobertura y tratamiento del discurso de las fuentes en el conflicto indígena mapuche desde el discurso político" en BROWNE, Rodrigo y SILVA, Víctor (coords.): Monográfico "Comunicación Intercultural” en Revista Redes.Com, n 3. Sevilla, Instituto Europeo de Comunicación y Desarrollo, pp. 83-112.

- (2006): Comunicación participativa, Estado-Nación y democracia. Discurso, Tecnología y Poder. Temuco, Ediciones Universidad de La Frontera.

- (2008):“CComunicación y derecho: bases teórico-metodológicas para un análisis comparado del discurso jurídico-judicial (sentencias penales) y del discurso de la prensa (noticias policiales)" en DEL VALLE, Carlos y BROWNE, Rodrigo et al. (2008) (eds.): Contrapuntos y entrelíneas sobre cultura, comunicación y discurso. Temuco, Ediciones Universidad de La Frontera.

DRZEWIECKA, Jolanta y STEYN, Melissa (2009): Discourses of exoneration in intercultural translation” en Communication Theory, $\mathrm{n}^{0}$ 19. Urbana-Champaing, University of Illinois, pp. 188-218.

DE PABLOS COELLO, José Manuel (2008): "Propuesta de metodología para duelos mediáticos en periodismo político. Aplicación al tratamiento informativo de El País a la crisis entre Uribe y Chávez por los rehenes de las FARC (2007 2008)" en Estudios sobre el Mensaje Periodístico, n 14. Madrid, Servicio de Publicaciones de la Editorial Complutense, pp. 149-173.

FAIRCLOUGH, Norman (2003): "El análisis crítico del discurso como método para la investigación en ciencias sociales" en WODAK, Ruth y MEYER, Michael (2003): Métodos de análisis crítico del discurso. Barcelona, Gedisa, pp. 179-204.

FOUCAULT, Michel (1994): Vigilar y castigar. Madrid, Siglo XXI.

- (1999): “La gubernamentalidad” en Estética, ética y hermenéutica. Barcelona, Paidós.

GASCÓN I MARTÍN, Felip (2005): "De imaginarios y memorias olvidadas. Reflexiones sobre redes de comunicación e interculturalidad” en BROWNE, 
Rodrigo y SILVA, Víctor (coords.) (2005): Monográfico “Comunicación Intercultural” en Revista Redes.Com, $\mathrm{n}^{\circ}$ 3. Sevilla, Instituto Europeo de Comunicación y Desarrollo, pp. 69-82.

GLASSER, Theodore L.; AWAD, Isabel y KIM, John W. (2009): "The claims of multiculturalism and journalism'spromise of diversity" en Journal of Communication, $\mathrm{n}^{\circ}$ 59. Kentucky, Department of Communication, University of Kentucky, pp. 57-78.

GRANADOS MARTÍNEZ, Antolín (2006): "Reflexiones en torno al fenómeno migratorio" en LARIO, Manuel (2006): Medios de comunicación e inmigración. Murcia, Convivir sin racismos.

GRIMSON, Alejandro (2000): Interculturalidad y comunicación. Bogotá, Norma.

HALL, Edward T. (1959): The Silent Language. New York, Doubleday and Co.

IMBERT, Gérard (2006): "Nuevos imaginarios/nuevos mitos y rituales comunicativos: ‘la hipervisibilidad' televisiva” en Revista de Signis. Mitos y ritos en las sociedades contemporáneas, n 9. Barcelona, Gedisa, pp. 125-135.

ISRAEL GARZÓN, Estrella (2000): "Bases para el periodismo intercultural” en Revista Latina de Comunicación Social. La Laguna (Tenerife), $n^{\circ} 34$, octubre. Disponible en: http://www.ull.es/publicaciones/latina [fecha de consulta: 27 de febrero 2010]

- (2002): “Comunicación intercultural para la formación de periodistas” en Sala de Prensa, $\mathrm{n}^{\circ}$ 45, julio. Disponible en: http://www.saladeprensa.org [fecha de consulta: 27 de febrero 2010]

- (2004): "Comunicación intercultural y construcción periodística de la diferencia” en La iniciativa de Comunicación, marzo. Disponible en: http://comminit.com [fecha de consulta: 27 de febrero 2010]

- (2006): "Cuestiones interculturales en tiempos de globalización mediática: el indígena y la presidenta” en Estudio de Periodismo y Relaciones Públicas, nº 6. Viña del Mar, pp. 125-140.

McCOMBS, Maxwell (1996): "Influencia de las noticias sobre nuestras imágenes del mundo" en JENNINGS, Bryan y DOLF Zillmann (1996) (eds.): Los efectos de los medios de comunicación: investigaciones y teorías. Barcelona, Paidós.

MATTELART, Armand y MATTELART, Michèlle (1997): Historias de las teorías de la comunicación. Barcelona, Paidós.

MAYORGA, Alberto y GONZÁLEZ, Víctor (2005): “Medios de comunicación y discurso hegemónico. Una aproximación empírica para comprender la configuración mediática y representación discursiva del Perú en la prensa chilena”. Memoria del IV Seminario Latinoamericano de Investigación de la Comunicación: Urgencias latinoamericanas en investigación comunicacional. Perspectivas crítico-epistemológicas. Universidad Andina Simón Bolívar. Bolivia.

MAYORGA, Alberto y LEÓN, Carla (2007): "El malvado siempre es el otro: Perú y su construcción discursiva en la prensa chilena” en Revista Universum, № 22 Vol. 2. Talca, Universidad de Talca, pp. 170-182. 
MEAD, G. H. (1973): Espíritu, persona y sociedad. Desde el punto de vista del conductismo social. Barcelona, Paidós.

MEYER, Michael (2003): "Entre la teoría, el método y la política. La ubicación de los enfoques relacionados con el ACD” en WODAK, Ruth y MEYER, Michael (2003): Métodos de análisis crítico del discurso. Barcelona, Gedisa, pp. 35-60.

MIGNOLO, Walter (2007): La idea de América Latina. Barcelona, Gedisa.

MIRALLES, Ana María (2001): Periodismo, opinión pública y agenda ciudadana. Bogotá, Norma.

NAÏR, Sami (2002): La inmigración explicada a mi hija. Barcelona, Círculo de lectores.

- (2006): Y vendrán... las migraciones en tiempos hostiles. Barcelona, Planeta.

NASH, Mary (2005): Inmigrantes en nuestro espejo. Inmigración y discurso periodístico en la prensa española. Barcelona, Icaria.

POTTER, Jonathan (1998): La representación de la realidad. Discurso, retórica y construcción social. Barcelona, Paidós.

RETIS, Jéssica (2006): "Mali y los inmigrantes malienses. Notas sobre la representación discursiva en el diario El País” en LARIO, Manuel (2006): Medios de comunicación e inmigración. Murcia, Convivir sin racismos.

RODRIGO ALSINA, Miquel (1989): La construcción de la noticia. Barcelona, Paidós.

- (1997): “Elementos para un comunicación intercultural” en Revista Cidob d'afers Internacionals, $\mathrm{n}^{\circ}$ 36, mayo, Barcelona.

- (1999): Comunicación intercultural. Barcelona, Anthropos.

- (2001): Teorías de la comunicación. Ámbitos, métodos y perspectivas. Barcelona, Aldea Global.

- (2006a): "Presentación: miradas interculturales" en RODRIGO ALSINA, Miquel: Comunicación, Revista Internacional de Comunicación Audiovisual, Publicidad y Estudios Culturales, no 4. Monográfico sobre "Comunicación Intercultural”. Universidad de Sevilla.

- (2006b): "El periodismo ante el reto de la integración” en LARIO, Manuel: Medios de comunicación e inmigración. Murcia, Convivir sin racismos.

RODRÍGUEZ VILLASANTE, Tomás (2008): "Las matrices y los tetralemas esquemas creativos para desbordar la complejidad social” en DEL VALLE, Carlos, BROWNE, Rodrigo et al. (2008) (eds.): Contrapuntos y entrelíneas sobre cultura, comunicación y discurso. Temuco, Ediciones Universidad de La Frontera.

ROMANO, Vicente (2000): “Poder y comunicación” en Revista Laberinto, $\mathrm{n}^{\circ} 7$. Málaga. Universidad de Málaga. Disponible en internet: http://laberinto.uma.es [fecha de consulta: 27 de febrero 2010]

SANTANDER MOLINA, Pedro (2005): "La credibilidad del periodismo al servicio de una nueva colonización: el mundo realginario" en Estudios sobre el Mensaje Periodístico, $\mathrm{n}^{\circ}$ 11. Madrid, Servicio de Publicaciones de la Editorial Complutense, pp. 181-192. 
SCHUTZ, A. y LUCKMAN, T. (2003): Las estructuras del mundo de la vida. Buenos Aires, Amorrortu.

SILVA, Víctor (2003): Comunicación e información (inter)cultural. La construcción de las identidades, la diferencia y el multiculturalismo. Sevilla, Instituto Europeo de Comunicación y Desarrollo.

SODRÉ, Muniz (1996): Reinventando la cultura. Buenos Aires, Gedisa.

(2009): A narração do fato: notas para uma teoria do acontecimento. Petrópolis, Rio de Janeiro, Vozes.

VAN DIJK, Teun (1990): La noticia como discurso. Comprensión, estructura y producción de la información. Barcelona, Paidós.

- (1996): Discourse, Racism and ideology. La Laguna, RCEI.

- (1997): Racismo y Análisis Crítico de los Medios. Barcelona, Paidós.

- (1998): Texto y contexto. Madrid, Cátedra.

- (1999): Ideología. Barcelona, Gedisa.

- (2002): "El análisis crítico del discurso y el pensamiento social” en Revista Atenea Digital, $\mathrm{n}^{\circ} 1$, primavera, pp. 18-24.

- (2003a): Racismo y discurso de las élites. Barcelona, Gedisa.

- (2003b): "La multidisciplinariedad del análisis crítico del discurso: un alegato a favor de la diversidad" en WODAK, Ruth y MEYER, Michael: Métodos de análisis crítico del discurso. Barcelona, Gedisa, pp. 143-178.

- (2003c): Dominación étnica y racismo discursivo en España y América Latina. Barcelona, Gedisa.

- (2006): “Discurso de las elites y racismo institucional” en LARIO, Manuel: Medios de comunicación e inmigración. Murcia, Convivir sin racismos.

- (2008): "Reproduciendo el racismo: El rol del racismo" en DEL VALLE, Carlos, BROWNE, Rodrigo et al. (eds.): Contrapuntos y entrelíneas sobre cultura, comunicación y discurso. Temuco, Ediciones Universidad de La Frontera.

VÁZQUEZ MEDEL, Manuel Ángel (1999): “Los medios de comunicación y la construcción social de la realidad” en CHAPARRO, Manuel (ed.) (1999): La democratización de los medios. Sevilla, EMA-RTV, pp. 123-145.

WODAK, Ruth (2003): "De qué trata el análisis crítico del discurso (ACD). Resumen de su historia, sus conceptos fundamentales y sus desarrollos” en WODAK, Ruth y MEYER, Michael: Métodos de análisis crítico del discurso. Barcelona, Gedisa, pp. 17-34.

WODAK, Ruth y MEYER, Michael (2003): Métodos de análisis crítico del discurso. Barcelona, Gedisa.

ZAPATA-BARRERO, Ricard y VAN DIJK, Teun (2008): Discurso sobre la inmigración en España. Los medios de comunicación, los parlamentos y las administraciones. Barcelona, Fundación Cidob. 